\title{
Increasing inclusion in early childhood: Key Word Sign as a communication partner intervention
}

\author{
Kathy Cologon and Zinnia Mevawalla \\ Department of Educational Studies, Macquarie University, Australia
}

The importance of communication partner intervention to support the successful implementation of augmentative and alternative communication (AAC) strategies has been established. Despite this, limited knowledge and use of AAC form serious barriers to inclusion. In this paper, we investigate the potential for the use of key word signing (KWS), one common form of AAC, as a communication partner intervention with pre-service early childhood teachers. In this study 196 pre-service early childhood teachers were taught KWS as an AAC strategy, along with approximately 80 Auslan signs. Participants were asked to develop ideas for implementing KWS in early childhood settings. Using participant journal entries, we conducted thematic analysis to investigate the perceived impact of using KWS in early childhood practice. Participants reported the belief that KWS was beneficial for supporting communication development. Participants identified that using KWS can facilitate inclusive approaches through reducing barriers to participation, valuing diversity, and supporting a sense of belonging. Additionally, participants reported that engaging with inclusive approaches to using KWS formed a catalyst for fostering openness to inclusion more broadly. Overall, the findings demonstrate that approaching KWS as a communication partner intervention holds potential for contributing to the conditions for inclusion in early childhood settings in line with social relational and human rights models of disability. Implications for teacher education and inclusive practice are discussed, as are the limitations of this study.

Key words: manual signing and gesture, early childhood education, inclusive education, social relational model of disability, human rights model of disability, communication partner intervention

\section{Introduction}

In this study, 196 pre-service early childhood teachers were taught to use manual signing as an augmentative communication strategy, and then asked to explore ways to implement this strategy in inclusive early childhood experiences. Participant perceptions of the implications of using manual signing in early childhood settings are reported in this paper. In the analysis, we engage with social relational and human rights models of disability. While this study addresses only a very micro aspect of the complex considerations of both these models, it nonetheless provides a window into some possibilities for the application of these models in supporting genuinely inclusive education.

\section{Augmentative and alternative communication}

Augmentative and alternative communication (AAC) involves the use of strategies to augment existing communication, alongside or as an alternative to spoken language, in order to facilitate participation and choice (Beukelman and Mirenda 2013). AAC involves the use of aided and unaided strategies and includes all forms of communication, other than oral speech, that are used to express thoughts, needs, feelings, desires, choices and ideas.

Gesture and manual sign are examples of 'unaided AAC', while 'aided AAC' involves the use of low and high technology. 'Low-tech' AAC systems include the use of 
pictures, communication boards or books and simple electronic devices. For example, single switch speech generating devices. 'High-tech' AAC systems include electronic devices or software that enable complex communication through speech and print generating options.

In this study, unaided AAC in the form of manual signing combined with speech was used. This approach, known in Australia as Key Word Sign, was developed from the key word signing system (KWS) more commonly referred to internationally as Makaton (Cornforth, Johnson and Walker 1974). Makaton involves the same KWS approach as Australian Key Word Sign, but with a different vocabulary (see:

http://www.scopevic.org.au/key-word-sign-australia/). Whilst Key Word Sign is the term specifically used in Australia at present, KWS is an internationally used term. In Australia KWS is taught using a vocabulary of signs appropriate to the Australian context drawn from Auslan, which is the language of the Deaf Community of Australia.

When using KWS, a sentence is spoken in full, whilst signs are used simultaneously to highlight only the key aspects of the message. This means that the signs are used in spoken language order, not signed language order, whereas signed languages (being 'visual' rather than 'spoken' languages) have their own grammatical forms. Thus, KWS involves 'borrowing' signs from a signed language to accompany spoken language (e.g. in Australia Auslan signs are used to augment the key words in a spoken sentence), rather than true use of a signed language. In each country where it is used, KWS takes key signs from the local sign language, coupled with natural gesture and a relevant spoken language, to support communication. KWS can be learnt through a combination of modelling and experience or use within everyday communication exchanges, and is generally considered relatively easy to learn (Dunst, Meter and Hamby 2011; Sheehy and Budiyanto 2014).

Despite concerns frequently expressed internationally by caregivers and practitioners that using KWS will inhibit speech development (Cress and Marvin 2003; Sheehy and Budiyanto 2014; Sheehy and Duffy 2009) or result in stigmatisation of children (Sheehy and Budiyanto 2014; Sheehy and Duffy 2009), research with diverse groups of children provides evidence that using KWS facilitates early communication, increased vocabulary and facilitates shared communication (Cress and Marvin 2003; Dunst et al 2011; Powell 1999; Vandereet, Maes, Lembrechets, and Zink 2011). Additionally, for many children, sign and gesture provide a bridge to later oral communication, with signing decreasing as oral language increases (Galeote, Sebastián, Checa, Rey and Soto 2011; Vandereet et al. 2011; Zampini and D'Odorico 2009).

When implemented inclusively, wherein all people within the given education setting use and learn sign together, the use of KWS has not been found to lead to stigmatisation (Brereton 2008). The belief that KWS would lead to stigmatisation has been found to be associated with exclusionary views and practices. For example, the belief that KWS should only be taught to children who have been identified as having impairments that impact on communication (Sheehy and Budiyanto 2014).

Implementing AAC strategies such as KWS has been shown to have considerable positive outcomes for successful shared communication and associated participation and development. However, Light and McNaughton (2015, p. 92) identify the need for, and absence of, 'real-life' AAC intervention with communication partners, arguing that "[i]ntervention is required to eliminate attitude, practice, and policy barriers that limit the participation of individuals who use AAC". Addressing these barriers within early childhood is an important part of inclusive education.

\section{Inclusion and communication}


Confusion around the meaning of 'inclusive education', and the frequent misappropriation of the term, has been well documented (Cologon and Salvador 2016). However, it has been established that, while a necessary starting point, inclusive education is about much more than placing children who may experience barriers to full inclusion alongside those who do not experience such barriers (Armstrong and Barton 2008; Cologon 2014a; Beckett 2009; D'Alessio 2011). Indeed, consistent with a human rights model of disability (Degener 2016), genuine inclusive education requires embracing and addressing all aspects of human diversity through attitudinal, structural, relational and environmental accommodations. Inclusive education is a 'big idea', but it is lived out in everyday moments in the interactions between people and environments (Cologon 2014a).

Drawing together the many different facets of the lived experience of inclusion and exclusion, in research in Australia with 121 families who experience disability, Cologon (2014b) found that genuine inclusion can be understood as belonging, participation, opportunity, and recognised and valued contribution. Since supporting shared communication is central to enabling belonging, participation, opportunity and recognised and valued contribution, or in other words to 'genuine inclusion', the use of AAC strategies can be understood as fundamental to addressing children's rights to inclusion in the early years.

Sharing and exchanging thoughts and ideas, emotions, needs, likes and dislikes can occur through many different forms of communication. However, in a phonocentric society (see Derrida 1974), in which spoken language is generally valued above all other forms of communication, there are significant barriers to inclusion for people who communicate using AAC and other non-verbal mediums of communication.

A human rights-based perspective sheds light on the seriousness of these barriers. A group of adults who experience disability, in a guidebook for personal assistants regarding communication, discussed the right to freedom from torture, inhuman or degrading treatment, expressing the following:

"Consider how degrading and inhuman it is for year after year to go by without anyone really trying to communicate with you, except maybe just about your basic needs. If no-one takes the time to find out what you are thinking, or assists you to express your views, or just chat with others, this is treating you as if you were not a full human being." (SCOPE UK 2002, p. 2)

While this statement was written about adults, it is pertinent in relation to people of all ages.

This group from the UK went on to note:

"We are used to people saying we cannot communicate, but of course they are wrong. In fact we have powerful and effective ways of communicating and we usually have many ways to let you know what it is we have in mind. Yes, we have communication difficulties, and some of those are linked with our impairment. But by far the greater part of our difficulty is caused by 'speaking people' not having the experience, time or commitment to try to understand us or to include us in everyday life. You can imagine how tough this can be." (SCOPE UK 2002, pp. 1-2)

Consistent with the experiences of these adults, it is not uncommon for 'speaking people' to erroneously assume that if a child does not speak then that child cannot communicate. A common response when a breakdown in shared communication is identified is to focus on the person who does not speak. Conversely, as highlighted above, focusing on the communication partners - many of whom are 'speaking people' - is critical to achieving shared communication (Kent-Walsh, Murza, Malani and Binger 2015). However, where communication partners do not have knowledge of, or confidence in using, AAC strategies this consequential lack of access to shared communication is a serious barrier to genuine 
This is a peer-reviewed, accepted author manuscript of the following article: Cologon, K., \& Mevawalla, Z. (2018). Increasing inclusion in early childhood: key word sign as a communication partner intervention. International Journal of Inclusive Education, 22(8), 902-920. https://doi.org/10.1080/13603116.2017.1412515

inclusion (Batorowicz, Campbell, von Tetzchner, King and Missiuna 2014; Kent-Walsh et al. 2015).

The human right to freedom from torture, inhuman or degrading treatment, discussed above, is one of many examples of human rights relating to communication. This right has long been enshrined in international human rights law, including in Article 37 of the UN Convention on the Rights of the Child (CRC) and in Article 15 of the UN Convention on the Rights of Persons with Disabilities (CRPD). This right has direct relevance to consideration of communication, including AAC. In more recent times, communication rights have been explicated in relation to education in General Comment 4 on the CRPD, which addresses the right to inclusive education (Article 24). For example, paragraph 22 of General Comment 4 stipulates that the entire education system, from early childhood onwards, must be accessible in all aspects, including with regards to communication.

As Degener (2016) argues, a human rights model of disability is based on a principle of transformative equality, incorporating but also going beyond both formal equality (for example, legal rules and regulations to ensure equality) and substantive equality (for example, addressing social barriers). Thus, not only are barriers to the immediate inclusion of an individual addressed, but positive measures are also taken to change structural and systemic barriers and address underlying power imbalances. Given the reach and implications of communication access or inaccessibility, if AAC was incorporated not only when a need arose in relation to an individual, but as a valued and ongoing aspect of communication in all education settings, this would facilitate genuine and relevant accessibility, and address concerns about stigma that may be experienced in situations where only some children sign. Such an approach would also form a positive initiative that may have the potential for genuine change including in relation to hierarchical power structures, which is key to transformative equality. Importantly, it has been demonstrated that AAC strategies, specifically including KWS, can be used to support inclusive educational practices (Brereton 2008; Sheehy and Budiyanto 2014). Consequently, while the use of KWS is only one aspect of AAC and one potential approach to inclusive communication approaches, a universal approach to AAC holds the potential for transformative equality, albeit on a micro (though certainly not insignificant) level, and thus also for contributing to the realisation of one aspect of human rights.

\section{The social relational experience of disability and a human rights model}

The human rights model of disability has been described as an extension of a social model of disability (Degener 2016). A social relational model of disability also extends on the traditional social model (Cologon and Thomas 2014). Together these provide potentially useful tools for understanding and bringing about inclusion in practice in all areas, including in the area of communication.

Many people who use AAC experience frequent and widespread exclusion (Light and McNaughton 2015). When considered from human rights and social model understandings of disability, these issues highlight the socially imposed barriers that prevent or inhibit the inclusion of people who experience disability and result in violations of human rights. In describing the social model of disability, Finkelstein (1975, p. 34) explains that a "person is disabled when he or she is socially prevented from full participation by the way society is arranged". Considering this statement in light of communication, when spoken language is valued above all other forms of communication (phonocentrism) - at a systemic or interpersonal level - a person who does not use spoken language (or uses spoken language augmented with other forms of language) is disabled. Likewise, when AAC is not used adequately, or not recognised as valid communication, this results in violations of human 
rights at the individual and collective levels and becomes a site of disablement. For example, in research with children (aged 5 to 14 years) who use aided AAC strategies, Batorowicz et al. (2014) found that the lack of preparedness of communication partners to spend the time required for a child to express a communicative message, despite considerable efforts on the part of the child, was common and was a source of frustration and sadness for the children. Amongst others, early childhood teachers are important communication partners for young children and their families (Cologon 2014a). One strategy to contribute to the amelioration of the exclusion and human rights violations outlined above is for AAC to be taught across mainstream teacher education, including within early childhood teacher education.

Presently there is limited research in this area. However, whilst acknowledging the significance of the contextual diversity of the extant international research, research to date does hold promise for increasing inclusion through universal incorporation of AAC into education settings. Brereton (2008) investigated the effects of incorporating a form of KWS (using Signing Exact English) into one preschool classroom in the USA, through an in-depth case study, and found that the incorporation of sign increased participation and appreciation of diversity. In exploring the experiences of children in Canada who use aided AAC strategies, Batorowicz et al. (2014) found that children's interactions with people who knew how to communicate using AAC were positive and important to the children, but that the children changed from active to passive interaction when the communication partner was impatient, disinterested or did not know how to communicate. In research in Indonesia, within a larger project developing Signalong Indonesia (an Indonesian version of KWS), Sheehy and Budiyanto (2014) explored school teacher attitudes towards the use of KWS with children labelled with 'severe disability'. While teachers in this research did raise concerns regarding the stigmatising potential of using sign, overall teacher attitudes were positive and teachers expressed a desire to be taught to use KWS.

Removing (or at least reducing to the greatest extent possible) barriers to doing and being (including using AAC) has been found to be a key consideration in facilitating inclusive practice (Mackenzie, Cologon, and Fenech 2016). Barriers to doing and being are concepts which form key components of Thomas' social relational understanding of disability (Cologon and Thomas 2014; Thomas 2010). These concepts are pertinent to considerations of communication and inclusive pedagogy. Understandings of these concepts may also contribute to human rights approaches to inclusive education in addressing both individual and structural barriers against transformational equality.

Barriers to doing are physical and economic barriers that impose participation restrictions to limit access, for example, building access, access to the curriculum, or to shared communication strategies (Cologon and Thomas 2014). These barriers to doing relate to the environmental elements highlighted by Light and McNaughton (2015) as critical factors to address in implementing AAC strategies. For example, if a child communicates partially or fully through sign and no signing is used in the early childhood setting then that forms a barrier to doing as it will significantly inhibit genuine participation and inclusion given the lack of shared communication.

Barriers to being are inappropriate, hurtful or hostile behaviours that can occur in individual interactions, as well as at systemic or institutional levels (Cologon and Thomas 2014). Barriers to being have a negative impact on an individual's sense of self, thus affecting who or what an individual feels they can be (Thomas 2007). Thomas (2007) has referred to this process as 'psycho-emotional disablism'. Psycho-emotional disablism, or barriers to being, impact negatively on a person's self-esteem, confidence, sense of belonging, positive sense of self and may also impact negatively on the experience of impairment (Cologon and Thomas 2014). Consistent with Light (2003) and Light and 
McNaughton's (2014) model of communication competence, which acknowledges the impact of the dynamic interactions involved in communicative exchanges, there is a clear potential impact of such barriers to being on a child (and family) who signs if the children, staff and families within an education setting that the child attends not only do not use sign, but do not value sign, see the use of augmentative communication as a burden, are not prepared to incorporate sign into the setting, or are only prepared to incorporate it in a limited way, such that shared communication between all peers and teachers is not genuinely possible.

Impairment effects relate to activity restrictions that occur as a result of an individual's impairment (Thomas 2010). For example, when cerebral palsy impacts on the coordination of the muscles around the mouth and the tongue this may alter or prevent speech. Thomas points out that impairment effects are bio-social, however, they are usually thought of as biological only (Thomas 2010). For example, phonocentrism increases the activity restrictions, and thus the impairment effects, experienced by a person who uses a communicative form other than speech. By contrast, consider a signing person in a Deaf community - whereas in a hearing community communicating through sign instead of spoken language can constitute an impairment effect, within a Deaf community no such impairment effect exists. Importantly, a human rights model of disability, and the CRPD, clearly outline the fact that a person's impairment has no bearing on their status as a rights holder - human rights are universal and unconditional (Degener 2016).

While relatively little is known about the perspectives of children who experience disability regarding the barriers they face particularly in relation to communication, in research in the UK, Connors and Stalker (2007) interviewed 26 children aged 7-15 years to understand their views about and experiences of disability and impairment. The participants reported experiencing barriers to doing and being, as well as impairment effects. In the research by Connors and Stalker (2007) it was barriers to being that the children found most difficult. Indeed, barriers to doing and being form considerable obstacles to inclusion. As such, the process of inclusion involves an ongoing commitment to identifying and breaking down these barriers, alongside a recognition of and commitment to the universal and unconditional nature of human rights.

While a child may be present within a local education setting, unless barriers to being and doing are addressed, the child will not be included. Spratt and Florian (2015, p. 94) argue that:

It has long been known that identifying certain children as having 'special needs' and providing additional targeted 'learning support' which is different from or additional to the learning experience of the majority of pupils, however well meant, has the unfortunate side effect of reinforcing the divide between those who are thought to be 'less able' from the rest of the school or classroom community, and stigmatising those who are classified as 'different'.

We would argue that this process of stigmatising is likely to result in the dehumanising imposition of barriers to being and in the practical creation of barriers to doing. Consequently, there is a need to adopt a human rights approach in which the needs of individuals are addressed within the context of a pedagogy of 'everybody'. Thus, we suggest taking the approach of universal design for learning, in which the needs of all are incorporated into every educational experience, rather than learning plans which cater for 'most' and 'some' (Spratt and Florian 2015).

Based on this alignment of the human rights model of disability (Degener 2016), the social relational understanding (Thomas 2010) of disability, and the concept of universal design for learning (Rose and Meyer 2000), in this study we explore data on 196 pre-service early childhood educators' perceptions of the implications of incorporating KWS into 
everyday early childhood experiences. Acknowledging the critical importance of the role of educators in facilitating shared communication and inclusion, our aim is to contribute to the developing knowledge of potential ways to address barriers to doing and being whilst honouring human rights as truly universal and unconditional - thus contributing to inclusive education through a pedagogy of 'everybody'.

\section{Methodology}

Responding to the gaps identified in the research, regarding the use of 'real-life' AAC intervention in everyday experiences with communication partners, in this study pre-service early childhood teachers were taught KWS. The first author is an accredited teacher of KWS in Australia.

A cohort of third year students who were undertaking a core unit of study on inclusive early childhood education as part of three or four-year teacher education degrees were taught to use KWS as an AAC strategy, alongside learning approximately 80 signs (drawn from Auslan, but used with spoken language) and provided with information regarding how to independently learn additional signs. These students were also asked to read Brereton's (2008) research paper, detailing a year-long case study in which sign language was used within a mainstream early childhood setting, and Cress and Marvin's (2003) paper addressing common concerns regarding the use of AAC strategies with young children. The students were then asked to develop ideas for using KWS in early childhood settings with children aged from birth to 12 years of age. The timing of the KWS aspects of the unit was intentionally planned to enable participants the opportunity to engage children directly with KWS during their guided experience placements.

Guided experience placements involve a block of 'practice teaching', during which pre-service teachers are supervised and mentored in the role of teacher in an education setting. In this case the participants undertook a three-week placement in either a prior to school or primary school early childhood setting. Many of the participants also worked in early childhood settings on an ongoing basis (for example, with diploma or certificate qualifications, whilst working towards their teaching degrees), and thus could incorporate and reflect on using KWS in an ongoing way. However, implementing the intervention prior to the guided experience placement enabled the full cohort to have the opportunity to use KWS in practice. KWS was incorporated informally into the guided experience. Given the variations and constraints of this arrangement, participants were asked to reflect on the use, as well as the potential impact, of KWS on early childhood practice.

In this paper we investigate participant perceptions of the implications of implementing KWS in everyday early childhood experiences, addressing the question: What do the participants in this study perceive to be the impact of using KWS in early childhood experiences and settings?

\section{Sampling and data collection}

A convenience sample was drawn from an undergraduate cohort of students undertaking study in order to qualify as 'mainstream' early childhood teachers in prior-to-school and/or primary school settings. As part of the unit of study on inclusive education, the students were required to write a journal weekly throughout the semester (over 15 weeks). All students in the cohort were invited to participate. The students who elected to participate in the research volunteered their journal reflections to be used for the purposes of this study.

While journal writing and learning KWS were compulsory parts of the course, participation in the research was optional. To avoid any perceived coercion and to reduce the likelihood of participants providing responses that they believed were 'desired' by the 
teaching staff (who were also the researchers), the pre-service teachers were only informed of the study and invited to participate at the conclusion of the semester. The student cohort was informed that the teaching staff would not know whether they chose to participate until after the conclusion of the final grading processes, and anonymity was assured. Ethics approval was obtained from the University Human Research Ethics Committee.

\section{Participants}

One hundred and ninety-six pre-service teachers, in a cohort of 214 , volunteered to participate in this research. This response rate was higher than anticipated, creating a relatively large sample for a qualitative study.

The high response rate may be due, at least in part, to the fact that participants were not required to undertake any additional tasks in order to participate (other than signing a consent form). The level of enthusiasm expressed by the participants for the KWS aspects of the unit may also be a contributing factor to the high response rate.

The majority of participants identified as female with three participants identifying as male. There was a mixture of domestic and international students in the sample, with the majority enrolled as domestic students. The participants were studying to become early childhood teachers within general education settings, rather than segregated special education settings.

\section{Analysis}

We conducted thematic analysis in three stages using NVivo, a computer assisted data analysis software program. Initially, strong familiarity and immersion was obtained through multiple readings of participants' responses. Subsequently, we developed codes and categories to "reflect the meaning of the retrieved words and phrases" (Yin 2009, p. 128). The development of codes and categories involved constant 'backtracking' (Yin 2009), that is, multiple revisions of coded data and themes to ensure consistency of interpretation and meanings. Engaging in a process of constant revision and comparison enabled identification of repetitions and patterns emerging from the data as themes (Ryan and Bernard 2003). For the final stage of data analysis, we repeatedly reviewed, refined and then considered the themes in light of the social relational and human rights models of disability, combining to form a process of inductive and deductive analysis (Hatch 2002). We sought overlapping themes and 'rival evidence' to ensure the authenticity and accuracy of themes. We analysed the entire dataset to ensure that generated themes accounted for all evidence (Yin 2009). Clear, strong themes emerged from the data, thus it is likely that saturation (Glaser and Strauss 1967) would have been reached with a smaller sample. However, we did not wish to exclude anyone and the sample created the opportunity to gain the perspectives of a diverse group, a benefit that we considered outweighed the challenges of an unwieldy sample size.

\section{Findings}

In the findings emerging themes regarding the perceived impact of using KWS in early childhood experiences and settings are considered. We also explore the findings in light of the social relational and human rights models of disability.

\section{The perceived impact of using KWS in early childhood experiences and settings}

Two major themes emerged regarding the impact of using KWS in early childhood experiences. Firstly, participants reported beliefs that KWS is beneficial for supporting successful shared communication and facilitating language development. Secondly, participants perceived benefits of KWS for enabling inclusive practices and reported the view 
that KWS facilitated the valuing of diversity in children, and the valuing of diverse forms of communication. These findings are consistent with the background provided through Brereton's (2008) study and the information provided in Cress and Marvin (2003). However, in this research the participants were required to go beyond reviewing research to learn, use and reflect on the impact of the use of KWS in early childhood practice.

Supporting successful shared communication and facilitating language development As noted above, caregivers and practitioners, including teachers, have previously been found to express concerns that using KWS will inhibit speech development (Cress and Marvin 2003; Sheehy and Budiyanto 2014; Sheehy and Duffy 2009). However, in line with research findings demonstrating that using KWS facilitates early communication, increased vocabulary and shared communication (Cress and Marvin 2003; Dunst et al 2011; Powell 1999; Vandereet et al. 2011), these concerns were not raised by the participants in the present study. While some participants particularly focused on the importance of KWS for children identified as having speech and language impairments, other participants highlighted the perceived benefits for all children's language development. Participants focused on receptive and expressive language in terms of supporting young children in their understanding and meaning-making and in supporting children in expressing emotions and in self-expression more generally. For example:

\begin{abstract}
"The use of KWS in a setting can assist children with understanding language and communication and also increases their ability to communicate amongst each other and with those who experience a disability or impairment." (B.B.)
\end{abstract}

"When educators valued and understood alternate forms of communication it allowed for more meaningful communication with children and supports an inclusive environment." (E.I.)

While it is unsurprising that the participants did not perceive KWS to be detrimental to language and communication development, since this common concern was addressed in the teaching of the participants, the perspectives of the participants went beyond this, recognising the active benefits of KWS for shared communication in early childhood settings.

Such universal engagement with KWS outlines possibilities for a 'pedagogy of everybody' through which barriers to doing and being might be addressed. For example, by providing accessible communication and curtailing negative attitudes towards the use of AAC. Reiterating the view that the right to communicate is a human right, this focus on children and educators 'understanding' one another may have benefits for embracing human diversity and thus, creating a sense of belonging in early childhood spaces. Moreover, from a social relational perspective, such a 'pedagogy of everybody' highlights the importance of the role of communication partners, particularly educators, in not only fostering avenues for meaning-making, but also for enabling environments for, and mobilising actors to support, the development of genuinely inclusive experiences and practices.

\title{
Facilitating inclusive practices
}

Consistent with Brereton's (2008) finding that when implemented inclusively, the use of sign does not lead to stigmatisation, participants in the present study noted the benefits of KWS for enabling inclusive practices and facilitating valuing of diversity, both in terms of broader diversity in children and in valuing diverse forms of communication. This is in contrast to previous research in which teachers were found to have concerns that using KWS may result 
in stigmatisation of children (Sheehy and Budiyanto 2014; Sheehy and Duffy 2009).

Specifically, in the present study participants emphasised that using KWS can lead to a reduction of barriers and ensure participation of all children, supporting individual and group engagement, valuing diversity and facilitating a sense of belonging. For example:

"The removal of barriers occurs as it allows children to value communicating in different ways." (B.Q.)

"Having varied forms of communication from verbal to visual allows for adaptability and preparedness for every situation." (L.D.)

"For all children to participate, using signing encourages a sense of belonging within the learning community, valuing inclusive education." (I.T.)

As noted in the literature review, the notion that using KWS would lead to stigmatisation has been found to be associated with the belief that KWS should only be taught to children who have been identified as having impairments that impact on communication (Sheehy and Budiyanto 2014). Education and support is needed to address such misunderstandings. The inclusive approach to using KWS implemented in this study, and the opportunity to engage with a case example (Brereton 2008) of inclusive approaches prior to engaging with KWS in early childhood practice, may assist in ameliorating these concerns when teaching KWS to teachers and allied professionals.

In line with the discussion of American Sign Language (ASL) in Brereton (2008), participants in the present study noted the importance of approaching KWS with respect and sensitivity to the Deaf Community in making clear the differences between KWS and signed languages, in this case Auslan. Participants highlighted the possibilities for greater valuing of cultural diversity as "children explore the richness of diverse cultures" (A.P.). Participants recommended inviting a member of the local Deaf Community to share knowledge and perspectives with the children where possible. For example:

"A great way to introduce key word sign is by engaging the children in conversation about the diversity of languages. Discuss foreign languages such as French and German or other languages that may [be] represented in the centre. Explain to children, that not everyone communicates through words; some groups of people such as the [Australian] Deaf community speak through Auslan." (K.D.)

"Inviting a visiting member of the Deaf community to speak with the children, exposing them to a different culture and language." (C.O.)

This finding is of relevance to upholding Article 30(4) of the CRPD on cultural participation, for example, which requires recognition and support for "specific culture and cultural identity, including sign languages and deaf culture". By engaging inclusively with a broader understanding of valued communication, participants may be opening a space for addressing phonocentric barriers to doing and being, as well as examining avenues for transformative equality. For example, this starting point would make it possible to explore the fact that in a hearing community communicating through sign instead of spoken language constitutes an impairment effect arising from phonocentric discourses and unequal relations of power, whereas within a Deaf community no such impairment effect or discourse inequality exists. 
Consistent with concepts of universal design for learning, the recognition not only that the incorporation of KWS was beneficial for a range of children, but also within this the realisation of the possibilities of planning for all, not 'most' and 'some' children (Spratt and Florian 2015) - a pedagogy of 'everybody' - is important as a foundation for transformative equality.

A particularly salient finding was the extent to which participants reported that engaging with inclusive approaches to KWS was a catalyst for developing greater confidence and openness to understanding and engaging in inclusion more broadly. For example:

\section{"I feel better able to implement and create a more inclusive environment within the} classroom." (G.D.)

"Going forward, I would like to continue to question common practice, and what steps could be taken, no matter how small, to create a more inclusive environment." (M.X.)

"I feel that I have been challenged in how I, as an educator, can provide, incorporate and include more inclusive practices into my everyday work. Every week I have been going to work and sharing what I have learnt with my colleagues, sometimes I was able to inspire them and get them thinking in different ways and other times I was met with the challenge of opinions which did not think certain changes could happen in relation to creating inclusive education. I found myself having to fight for the cause, thus with the knowledge, understanding and determination I was able to demonstrate and show them how it is possible. By incorporating key word sign into daily practices, using pictures, adapting some routines and experiences we were working towards creating a more inclusive environment thus providing more inclusive education." (W.B.)

This finding demonstrates that using KWS may have potential for facilitating inclusion in relation to and beyond considerations of communication. The catalyst for advocacy of inclusion as a human and educational right is clear in participant comments which illuminate the imperative for breaking down barriers to doing and being in order to achieve transformative equality and inclusion.

Consistent with human rights and social relational models of disability, participants reported the benefits of using KWS to assist in breaking down barriers to doing and being through embracing and celebrating all aspects of human diversity and thus for bringing about inclusion. For example:

"Using signing within an early childhood setting can in fact benefit all children regardless of their ability to communicate, because it can offer more opportunities for participation, inclusivity, and valuing of difference and diversity." (K.F.)

"Implementing sign within an early childhood classroom helped children to understand and value diversity" (O.N.)

One participant, whilst addressing similar ground within the overall comment, summed this up, expressing that "Sign language benefits ...the entire learning community." (T.N.).

Finally, the participants highlighted the role of the teacher in learning, using and encouraging KWS within the early childhood setting, as exemplified through the statement: 
This is a peer-reviewed, accepted author manuscript of the following article: Cologon, K., \& Mevawalla, Z. (2018). Increasing inclusion in early childhood: key word sign as a communication partner intervention. International Journal of Inclusive Education, 22(8), 902-920. https://doi.org/10.1080/13603116.2017.1412515

"Incorporating KWS into an inclusive early childhood setting is achievable with an enthusiastic educator who is willing to learn and teach KWS in their classroom" (B.M.)

\section{Discussion and conclusions}

As noted earlier in this paper, early childhood teachers play a critical role in facilitating inclusion. Additionally, the importance of focusing on communication partners in achieving shared communication is well established (Batorowicz et al. 2014; Kent-Walsh et al. 2015). Indeed, the communicative efforts of adults and peers have been found to be important to, and also to alter the communicative attempts and approaches of, children who use AAC (Batorowicz et al. 2014). However, Light and McNaughton (2015) have identified the importance (and absence) of 'real-life' AAC interventions in everyday experiences with communication partners. Consistent with meta-analysis findings that confirm the importance of communication partner interventions (Kent-Walsh et al. 2015), this study contributes to addressing this gap by exploring the implications of supporting pre-service early childhood teachers (communication partners) in gaining knowledge and confidence in using KWS. Participant perceptions of using KWS inclusively in early childhood practice were explored. The participants in this study reported positive beliefs about KWS, including the view that KWS can be used to create opportunities for inclusive communication within early childhood settings.

The need for intervention to address the barriers to inclusion that are inherent in attitudes regarding the use of AAC has been raised in previous research (Light and McNaughton 2015; Sheehy and Budiyanto 2014). Attitudes towards the use of AAC are likely to impact not only on accessibility, and thus on barriers to doing, but also on individuals' experiences of barriers to being that may result from a negative approach or lack of valuing of multiple forms of communication. Given that barriers to being have a negative impact on an individual's sense of self and can affect who or what an individual feels they can be (Thomas 2007), these are serious considerations. It is noteworthy that, although negative attitudes have been identified in previous research (Cress and Marvin 2003; Sheehy and Budiyanto 2014; Sheehy and Duffy 2009), the participants in the present study reported positive or strongly positive attitudes about the use of AAC in early childhood education. Participants also frequently expressed a desire to further their knowledge and use of AAC. This is consistent with the findings of Sheehy and Budiyanto (2014) who found that teachers in Indonesia were interested in being taught KWS.

It is possible that several factors may have contributed to the development of positive attitudes towards AAC in the present study. These factors include: a) the introduction of KWS as a practical experience; b) providing research on AAC, including KWS; c) providing theoretical tools and lens for thinking about inclusion; and d) tasking the participants with developing inclusive strategies for implementation.

It would appear that the provision of research background and an in depth case example of the inclusive implementation of KWS in an early childhood setting may positively influence attitudes towards the use of KWS. Additionally, the high level of enjoyment of learning KWS expressed by many participants may also be a contributing factor. These are important considerations for both teacher education and also for the teaching of KWS more broadly.

In taking an inclusive approach to incorporating KWS in early childhood settings, participants emphasised the need for a respectful approach, mindful of the sensitivities in relation to Deaf culture and language. This is a serious consideration with implications for 
transformative equality. The historical devaluing of signed languages, and the barriers to being and doing imposed as a result, underlines the importance of careful and respectful reflection and action regarding the ways in which KWS is taught to professionals and, in turn, the ways in which early childhood teachers and other professionals introduce KWS to children. Many participants in this study engaged with the idea of introducing and acknowledging Auslan as an additional language and ensuring that the children, staff and families in the setting were aware of the differences between KWS and sign language and understood the notion of 'borrowing' signs from signed languages to enable KWS. This finding builds on Brereton's (2008) research showing the benefit of the inclusive use of sign for children's appreciation of diversity.

Light and McNaughton (2015) highlight the need to address the environmental factors that impact on the lives of people who use AAC. In line with these concerns, the findings of this study can be viewed as demonstrating the potential for using KWS effectively in reducing or removing barriers to doing, predominantly in relation to creating access to shared communication. Using KWS universally in early childhood settings - a pedagogy of 'everybody' - can contribute to addressing the common barriers to social and educational inclusion that have been found to occur when communication partners do not have knowledge of, or confidence in using, AAC strategies resulting in a lack of access to shared communication (Batorowicz et al. 2014; Kent-Walsh et al. 2015).

As noted earlier in this paper, a human rights model of disability, and the CRPD, is predicated on the understanding that a person's impairment has no bearing on their status as a rights holder and a recognition that human rights are universal and unconditional (Degener 2016). Participant responses to implementing KWS, consistent with a universal design approach to communication, indicate the potential contribution that this approach can make to upholding the rights of all people equally.

The perception that incorporating KWS can benefit the full early childhood community opens up the possibility that inclusive approaches to AAC implementation, such as this one, may contribute to the broader social change that Light and McNaughton (2015) have argued is necessary in moving forward in AAC practices and in bringing inclusion to a reality. This social change, and the associated processes of transformative equality, is directly related to addressing barriers to being that people who use AAC may experience at both individual and systemic levels on account of the deficit perspectives frequently perpetuated regarding AAC. As noted earlier, paragraph 22 of General Comment 4 on the CRPD stipulates that the entire education system, from early childhood education onwards, must be accessible in all aspects, including in regards to communication. The universal availability of KWS across all early childhood settings (and arguably, by extension, all education settings) would make a worthwhile contribution towards achieving this accessibility and thus to upholding this human right, for all.

Embracing human diversity is a fundamental aspect of a human rights model of disability (Degener 2016). Consistent with Brereton's (2008) findings, the participants in this study found that KWS can be used to facilitate valuing of diverse forms of communication, and of human diversity more broadly, therefore potentially reducing or removing barriers to being whilst facilitating a sense of belonging and a socially just approach to education. This finding is also consistent with the underlying tenets of inclusive education and with the move from deficit based understandings of disability towards social relational and human rights based understandings, which highlight the socially constructed nature of barriers and the real possibilities available to settings for supporting inclusion. Indeed, participants identified that using KWS could facilitate inclusive approaches in and of itself. Additionally, participants reported that this approach formed a catalyst for fostering openness to inclusion more 
broadly. If, as discussed earlier, the process of inclusion involves identifying and breaking down barriers to doing and being from an understanding of the value of human diversity and the universality and unconditional nature of human rights, then it may be that practicing this process could enable teachers to better understand and apply disability theory to everyday educational experiences. This finding is consistent with the arguments of Mackenzie et al (2016).

The findings of this study have implications for early childhood and AAC practices, as well as for teacher education. Closer cross-disciplinary collaboration may be beneficial in addressing the barriers that children who use AAC face in and beyond education settings. Incorporating AAC strategies, alongside theoretical tools drawn from previous research, as a communication partner intervention within teacher education for all teachers may facilitate inclusion. However, further research is needed.

\section{Limitations}

There are several limitations to this study. Critically, barriers to being and barriers to doing are concepts that are used to describe the lived experience of disability. However, this study only investigated the perceptions reported by pre-service early childhood teachers about using KWS inclusively in early childhood settings. In order to understand the actual impact of inclusive implementation of KWS on barriers to doing and being in early childhood settings, the perspectives of children who use AAC are essential. This is an important area for further research. Nonetheless, the present study contributes to forwarding inclusive AAC practice through considering ways in which teachers can work to identify and address barriers to doing and being in early childhood.

Additionally, in this study only perceptions reported by pre-service teachers, not actual classroom practices and outcomes, were investigated. This is both a limitation of this study and a focus area for future research. Furthermore, while many participants worked in early childhood settings, because the participants were pre-service teachers many others spent only limited blocks of time teaching in early childhood settings. Further, larger-scale, research with in-service teachers is required to consider the longer-term impacts of the inclusive implementation of KWS in early childhood settings, including the impact on the communication practices of other educators within each setting.

Previous research has identified considerable individual variation in preferences for the use of various forms of aided and unaided AAC (van der Meer, Sigafoos, O'Reilly and Lancioni 2011). While it is likely that aspects of aided AAC are, or will be, used by the preservice early childhood teachers who participated in this study (for example, picture schedules and photographs to support communication), in this study we investigated preservice teachers' perceptions on using unaided AAC in the form of KWS. Future research could investigate the use of multiple forms of aided and unaided AAC within early childhood settings, and the impact of providing education to teachers regarding aided AAC strategies to further facilitate inclusion.

One potentially considerable limitation of this study is the extent to which the findings align with Brereton (2008) and Cress and Marvin (2003), since the participants were asked to read these papers prior to learning, using and reflecting on the use of KWS. This raises the question of whether the participants simply reported what they were taught. However, beyond 'regurgitation' of what they had read, the participants were able to demonstrate interpretation and application of learning through enthusiastic engagement with KWS as a tool for both communication and inclusion more broadly, in the context of their experiences (including their guided experience) and prior knowledge of early childhood. Consequently it can be argued that, rather than a limitation of the study, the use of theoretical 
tools such as these research papers can be beneficial for engaging with and applying the practical aspects of KWS in an inclusive way. Nonetheless, further research is clearly needed to address the ongoing impact of this approach over a longer period of time and with inservice, not only pre-service, teachers.

Finally, it is important to acknowledge that although all efforts were made to minimise any influence on the study of the fact that the participants were also pre-service teachers engaging with KWS as part of their studies, to some extent the unanimously positive perspectives in the study may inevitably be influenced by this context. It is also possible that the 18 members of the cohort who chose not to participate held less positive views. Nonetheless, the findings of the study support the idea that incorporating KWS into preservice teacher education can have positive outcomes that are consistent with social relational and human rights approaches to inclusion.

\section{Conclusion}

Participants in this study identified a multitude of positive implications of using KWS inclusively (that is, where all people in a setting learn and use sign) in early childhood experiences and settings. Exploring pre-service early childhood teachers' views, through the application of social relational and human rights models of disability in this study, has shown that early childhood teachers, as key communication partners (Cologon 2014a), have the potential to reduce or remove barriers to being and doing in order to foster inclusion. This inclusive implementation of KWS in early childhood is consistent with a human rights model of disability, recognising the need for universal accessibility and for making active changes to address underlying power hierarchies, for example those which exist when communication access is conditional. Participants' orientation to social justice and the importance of belonging underpinned the understanding of inclusion evident in this study.

The findings of this study have implications for teacher education. Providing a comprehensive introduction to KWS as an integral component of teacher education may address concerns regarding stigmatising children who use sign. Taking this approach may also facilitate greater inclusion for all. In understanding the findings of this study, the importance of using both theoretical and practical tools to support positive teacher engagement with AAC is evident. This finding has implications not only for the teaching of KWS as part of teacher education, but also for the teaching of KWS and other AAC strategies more broadly.

Overall, the findings of this study demonstrate the potential that an inclusive approach to KWS may hold for increasing pre-service early childhood teachers' knowledge of, and confidence in using, AAC strategies. Communication, in all its forms, is a fundamental aspect of everyday interactions, and thus, is integral to inclusion and the actualisation of human rights. Given that early childhood teachers are important communication partners, and are in a powerful position to facilitate peer communication and environments which respect and value cultural and communicative diversity, this finding holds significant implications for inclusive practice in relation to AAC. In conclusion, while there are numerous considerations for further research, it is clear that there are many possibilities for breaking down barriers to doing and barriers to being to contribute to the upholding of human rights and bringing about of genuine inclusion in early childhood practice through the implementation of AAC supports. As such, the inclusive implementation of KWS in early childhood may be an example of the living out of the 'big idea' of inclusion in everyday moments.

\section{References}


Armstrong, F., and L. Barton, 2008. "Policy, experience and change and the challenge of inclusive education: the case of England." In L. Barton and F. Armstrong (Eds.), Policy, experience and change: cross-cultural reflections on inclusive education (pp.5-18). London, UK: Springer

Batorowicz, B., F. Campbell, S. von Tetzchner, G. King, and C. Missiuna. 2014. "Social participation of school-aged children who use communication aids: the views of children and parents." Augmentative and Alternative Communication 30 (3): 237-251. doi:10.3109/07434618.2014.940464

Beckett, A. E. 2009. “'Challenging disabling attitudes, building an inclusive society': Considering the role of education in encouraging non-disabled children to develop positive attitudes towards disabled people." British Journal of Sociology of Education 30 (3): 317-329. doi:10.1080/01425690902812596

Beukelman, D., and P. Mirenda. 2013. Augmentative and alternative communication: Supporting children and adults with complex communication needs (4th ed.). Baltimore: Paul H. Brookes.

Brereton, A. 2008. "Sign language use and the appreciation of diversity in hearing classrooms." Early Years: Journal of International Research and Development 28 (3): 311-324. doi:10.1080/09575140802393702

Cologon, K. 2014a. "Better together: Inclusive education in the early years." In Inclusive education in the early years: Right from the start, edited by K. Cologon, 3-26. South Melbourne: Oxford University Press.

Cologon, K. 2014b. "Not just being accepted, but embraced': Family perspectives on inclusion." In K. Cologon (Ed) Inclusive education in the early years: Right from the start (pp.91-114). South Melbourne: Oxford University Press.

Cologon, K., and C. Thomas. 2014. "Ableism, disablism and the early years." In Inclusive education in the early years: Right from the start, edited by K. Cologon, 27-48. South Melbourne: Oxford University Press.

Cologon, K. and A. Salvador. 2016. "An inclusive approach to early childhood is essential to ensuring equity for all children." Global Report on Equity and Early Childhood (pp. 51-76). Netherlands: Consultative Group on Early Childhood Care and Development. http://www.fundacionoportunidad.cl/assets/uploads/archivos/4f551-cgglobalfullreportenglish-r2-web-lowres.pdf.

Connors, C. and K. Stalker. 2007. "Children's experiences of disability: Pointers to a social model of childhood disability." Disability and Society 22 (1): 19-33. doi:10.1080/09687590601056162

Cornforth, A.R.T., K. Johnson, and M. Walker. 1974. "Teaching sign language to the deaf mentally handicapped." Journal of the Institute of Mental Subnormality 2 (1): 23-25. doi:10.1111/j.1468-3156.1974.tb00075.x

Cress, C., and C. Marvin. 2003. "Common questions about AAC services in early intervention." Augmentative and Alternative Communication 19 (4): 254-272. doi:10.1080/07434610310001598242

D'Alessio, S. 2011. "Inclusive education in Italy: A critical analysis of the policy of integrazione scolastica”. Rotterdam, Netherlands: Sense Publishers.

Degener, T. 2016. "Disability in a human rights context." Laws 5 (3): 35-59. doi: 10.3390/laws5030035

Derrida, J. 1974. Of Grammatology. Translated by G. Spivak. Baltimore: Johns Hopkins University Press.

Dunst, C. J., D. Meter, and D.W. Hamby. 2011. "Influences of sign and oral language interventions on the speech and oral language production of young children with 
disabilities." CELL Reviews 4 (4): 1-20.

http://www.earlyliteracylearning.org/cellreviews/cellreviews_v4_n4.pdf

Finkelstein, V. 1975. "Phase 2: Discovering the person in 'disability' and 'rehabilitation'." Magic Carpet 27 (1): 31-38. http://disabilitystudies.leeds.ac.uk/files/library/finkelstein-finkelstein4.pdf

Galeote, M., E. Sebastian, E. Checa, R. Rey, and P. Soto. 2011. "The development of vocabulary in Spanish children with Down syndrome: Comprehension, production and gestures." Journal of Intellectual and Developmental Disability 36 (3): 184-196. doi:10.3109/13668250.2011.599317

Glaser, B. G., and A. L. Strauss. 1967. The discovery of grounded theory: Strategies for qualitative research. Piscataway, New Jersey: Transaction

Hatch, J.A. 2002. Doing qualitative research in educational settings. Albany: State University of New York Press.

Kent-Walsh, J., K. A. Murza, M. D. Malani, and C. Binger. 2015. "Effects of communication partner instruction on the communication of individuals using AAC: A metaanalysis." Augmentative and Alternative Communication 31 (4): 271-284. doi:10.3109/07434618.2015.1052153

Light, J. 2003. "Shattering the silence: Development of communicative competence by individuals who use AAC." In Communicative competence for individuals who use AAC: From research to effective practice, edited by J. C. Light, D. R. Beukelman, and J. Reichle, 3-38. Baltimore, MD: Paul H. Brookes.

Light, J., and D. McNaughton. 2014. "Communicative competence for individuals who require augmentative and alternative communication: A new definition for a new era of communication." Augmentative and Alternative Communication 30: 1-18. doi:10.3109/07434618.2014.885080

Light, J., and D. McNaughton. 2015. "Designing AAC research and intervention to improve outcomes for individuals with complex communication needs." Augmentative and Alternative Communication 31 (2): 85-96, doi:10.3109/07434618.2015.1036458

Mackenzie, M., K. Cologon, and M. Fenech. 2016. “"Embracing everybody': Approaching the inclusive early childhood education of a child labelled with Autism from a social relational understanding of disability." Australasian Journal of Early Childhood 41 (2): 4-12. http://www.earlychildhoodaustralia.org.au/our-publications/australasianjournal-early-childhood/

Powell, G. 1999. Current research findings to support the use of signs with adults and children who have intellectual and communication difficulties. http://www.makaton.org/aboutMakaton/research

Rose, D., and A. Meyer. 2000. "Universal design for individual differences." Educational Leadership 58 (3): 39-43. http://www.ascd.org/publications/educationalleadership.aspx

Ryan, G., and R. Bernard. 2003. "Techniques to identify themes." Field Methods 15 (1): 85109. doi:10.1177/1525822X02239569

SCOPE UK. 2002. The good practice guide, for support workers and personal assistants working with disabled people with communication impairments. London: Essex Coalition of Disabled People/Scope Research Department. http://www.scope.org.uk/sites/default/files/pdfs/Communication/Scope_guide_for_P As.pdf

Sheehy, K, and Budiyanto. 2014. "Teachers' attitudes to signing for children with severe learning disabilities in Indonesia." International Journal of Inclusive Education 18(11): 1143-1161. doi:10.1080/13603116.2013.879216 
Sheehy, K, and H. Duffy. 2009. "Attitudes to Makaton in the ages on integration and inclusion.” International Journal of Special Education 24 (2): 91-102. http://oro.open.ac.uk/19897/2/SheehyDuffy_Makaton_112009_No_2.doc

Spratt, J., and L. Florian. 2015. "Inclusive pedagogy: From learning to action. Supporting each individual in the context of "everybody'." Teaching and Teacher Education 49: 89-96. doi:10.1016/j.tate.2015.03.006

Thomas, C. 2007. Sociologies of disability and illness: Contested ideas in disability studies and medical sociology. Hampshire: Palgrave Macmillan.

Thomas, C. 2010. Medical sociology and disability theory. In New directions in the sociology of chronic and disabling conditions: Assaults on the lifeworld, edited by G. Scambler, and S. Scambler, 37-56. Basingstoke: Palgrave Macmillan

van der Meer, L., J. Sigafoos, M. F. O’Reilly, and G. E. Lancioni. 2011. “Assessing preferences for AAC options in communication interventions for individuals with developmental disabilities: A review of the literature." Research in Developmental Disabilities 32: 1422-1431. doi:10.1016/j.ridd.2011.02.003

Vandereet, J., B. Maes, D. Lembrechts, and I. Zink. 2011. "The role of gestures in the transition from one- to two-word speech in a variety of children with intellectual disabilities." International Journal of Language and Communication Disorders 46 (6): 714 - 727. doi:10.1111/j.1460-6984.2011.00050.x

Yin, R. K. 2009. Case study research: Design and methods. 4th Edition. Thousand Oaks, California: Sage.

Zampini, L., and L. D’Odorico. 2009. "Communicative gestures and vocabulary development in 36-month-old children with Down's syndrome." International Journal of Language and Communication Disorders 44 (6): 1063-1073. doi:10.1080/13682820802398288 